\title{
Religiousness and Quality of Life Among Older Adults of Different Ethnic Groups in Malaysia: A Five-Year Follow-up Study
}

\author{
Min Min Tan ${ }^{1,2}$ D Daniel D. Reidpath ${ }^{2,5} \cdot$ Rachel Sing-Kiat Ting ${ }^{3} \cdot$ \\ Pascale Allotey ${ }^{2,4} \cdot$ Tin Tin Su ${ }^{1,2}$
}

\section{Accepted: 23 July 2021}

(C) The Author(s), under exclusive licence to Springer Science+Business Media, LLC, part of Springer Nature 2021

\begin{abstract}
Research has shown that religion is associated with a better quality of life (QoL). This study aims to examine ethnic differences in the association between religion and the QoL of older adults in a predominantly Muslim population within a multicultural setting. Two-wave data of 3,810 participants consisting of mostly Muslims and older adults aged $\geq 55$ years were collected as part of the community health surveys conducted in 2013 and 2018 in the South East Asia Community Observatory (SEACO). Both cross-sectional analyses of baseline data and prospective analyses of longitudinal data were conducted. The associations between religiosity and quality of life were mainly positive in the cross-sectional analysis. In the two-wave analysis, religious importance was negatively associated with QoL among the Malays $(B=-1.103, S E B=0.029, p<.001)$ and the Chinese $(B=-0.160, S E B=0.043$, $p<.001$ ), and a belief in a higher power control was associated with better QoL among the Malays $(B=0.051, S E B=0.022, p<.005)$ and poorer QoL domains among the Indians (physical health: $B=-5.412, S E B=1.382, p<.001$; psychological: $B=-3.325, S E B=1.42, p<.001$; social relationship: $B=-5.548, S E$ $B=1.616, p<.001$; environment: $B=-2.586, S E B=1.288 ; p<.05$ ). Our study's mixed results suggest that religiosity is positively associated with quality of life in cross-sectional analyses. However, in longitudinal analyses, the results are different. Conclusions with regard to causality based on cross-sectional analyses may be misleading. Health promotion programs should continue to examine the effect of religiousness on health outcomes over time among aging populations across different ethnic groups.
\end{abstract}

Keywords Religion · Quality of life · Malaysia · Ethnicity

Min Min Tan

tan.minmin@monash.edu; minmin.tan@gmail.com

Extended author information available on the last page of the article 


\section{Introduction}

Quality of life (QoL) is a multifaceted construct. It is defined as "an individual's perception of their position in life in the context of the culture and value systems in which they live and in relation to their goals, expectations, standards and concerns" (World Health Organization, 2012). Research studies have found that ethnicity may influence the quality of life. Compared to their White counterparts, African-American older patients with arthritis reported a lower self-rated quality of life (Ibrahim et al., 2002). A person's religious and spiritual experiences might be another significant contributor to his or her quality of life. Koenig et al. (2012) reviewed 64 studies published between 2001 and 2021, only to find that 41 (64\%) studies identified a significant positive relationship between religiousness, spirituality and quality of life measures.

The majority of religion and quality of life studies were generally in White Christian populations. However, there has also been a recent increase in such studies in populations of other religions and ethnicities. In the context of Malaysia, a higher level of religiousness was found to be associated with better psychological well-being. Furthermore, religiousness moderated the association between chronic medical conditions and psychological well-being among older Muslims (Momtaz et al., 2012). A study of 321 Hindu older adults in Chennai, India, revealed that religiousness was associated with better well-being, and this relationship was mediated by psychosocial resources (Chokkanathan, 2013).

The association between religion and quality of life differs by ethnicity and religious affiliation. In the USA, church-based social support mediated the association between frequent religious attendance and higher life satisfaction among African Americans, but not in Afro-Caribbeans and non-Hispanic Whites (Assari, 2013). In a study conducted among the Chinese population in Taiwan, Buddhists reported a higher level of socially oriented subjective well-being, followed by Taoists, atheists, and Christians (Shiah et al., 2016). The variations in the association between religion and well-being might be due to cultural differences in the values of collectivism and strong-ties orientation. According to the Ecological Rationality Framework, different cultural groups (including ethnic groups) have adopted varying cognitive orientations specific and adaptive to their ecology. Their religiousness also differs on the continuum of internal orientation versus external orientation dimension and strong-ties versus weak-ties dimension (Ting et al., 2020). Hence, religiousness or religious importance is a significant moderator of quality of life across ethnic groups and religious affiliations.

\section{Current Study}

An increasing number of religion and health studies have started including populations other than White Christians. However, most of the previous studies that examined ethnic differences in religion and health among older adults were 
conducted among older White, older African American, and to a smaller extent, older Mexican American participants (Krause \& Hayward, 2016). There is a paucity of comparative studies conducted in populations of other ethnic groups and other religions such as Islam, one of the world's major religions. Among the studies on religion and health published since 2000, cross-sectional studies outnumber longitudinal studies by a six-to-one ratio (Koenig et al., 2012); hence, there is also a great need to examine longitudinal data.

Malaysia is a multicultural and multi-faith country. This multicultural landscape provides an opportunity to examine the intersectionality of religion and ethnicity and evaluate how it affects the quality of life. Many major religions such as Islam, Buddhism, Hinduism, and Christianity are practiced in Malaysia by specific ethnic groups (see study setting in Methods). However, the research on religion and health is still under-explored in Malaysia and several other Asian countries. It is unknown, for instance, whether older populations in Malaysia or other Asian countries experience similar health benefits from religion as those from Western countries. Given the influence of ethnicity and age on the quality of life and the importance of religion among older adults, this study first examined whether there were ethnic differences in the cross-sectional association between religion and quality of life among older adults living in a predominantly Muslim and multicultural setting. Second, two-wave longitudinal data were used to examine ethnic differences in the relationship between religion and changes in quality of life over time. Due to the ecological differences between different racial groups, we hypothesized ethnic differences between religion and quality of life among older adults in Malaysia.

\section{Methods}

\section{Study Setting}

Malaysia has 32.6 million people comprised of $69.3 \%$ Bumiputras (a category consisting of mainly Malay and minority indigenous peoples), $22.8 \%$ Chinese, $6.9 \%$ Indians, and 1.0\% other races (Department of Statistics Malaysia, 2019). Islam is practiced by $61.3 \%$ of the population (Department of Statistic Malaysia, 2011). Legally, all Malays are Muslims. The second-largest religious denomination in Malaysia is Buddhism (19.8\%) which is practiced mainly by Chinese, followed by Christianity (9.2\%), and lastly, Hinduism (6.3\%) whose devotees are mostly Indians (Department of Statistic Malaysia, 2011). The indigenous people are predominantly Christians (46.5\%) and Muslims (40.4\%) (Department of Statistic Malaysia, 2011).

\section{Sample}

The five-year follow-up study was conducted in the South East Asia Community Observatory (SEACO), a health and demographic surveillance system (HDSS) established in 2011 by Monash University and located in the district of Segamat, in the state of Johor in West Malaysia (Partap et al., 2017). It operates in five of the 11 
sub-districts of Segamat, namely Bekok, Chaah, Gemereh, Jabi, and Sungai Segamat, and covers $1,250 \mathrm{~km}^{2}$. The SEACO population is distinct from the national population; the percentage of individuals aged 20-45 years was lower than that of the national population, likely due to outmigration to seek better educational and working opportunities (Jahan et al., 2014). The SEACO HDSS conducts annual enumeration updates to collect sociodemographic and some health measures. Its 2020 update included 43,923 individuals living in 12,745 households. This study utilized the data collected as part of the community health surveys conducted during 2013 and 2018. Trained data collectors interviewed individuals living in the five sub-districts in which the SEACO HDSS operates the survey included questionnaire items about demographic characteristics, quality of life, comorbidities, and others. Waves 1 and 2 of the surveys included 25,168 and 24,710 participants, respectively. The participants included in this study (3,810 individuals) were limited to those aged $\geq 55$ years in 2013, who had participated in both surveys and were of Malay, Chinese, or Indian descent. This study was approved by the Monash University Human Research Ethics Committee (2013-3837-3646).

\section{Measures}

\section{Religiousness}

Two religious dimensions were included in this study. First, religious importance measured the self-rated importance of having an enriched religious/spiritual life ( 1 =Useful, but I can live without it; $2=$ Important; $3=$ Very important; $4=$ Essential, I cannot live without it). Second, belief in a higher power control measured the strength of a participant's belief in a higher power that determines the course of their lives $(1=$ Totally agree to $5=$ Totally disagree $)$. Belief in a higher power control was reversed-coded so that a higher score represented higher belief.

\section{Quality of Life}

Quality of life was measured using the 26-item WHOQOL-BREF scale, the short form of WHOQOL-100 developed by the World Health Organization (WHOQoL Group, 1998). There was one single-item measure of the general quality of life ("How would you rate your quality of life?") and another about self-reported health status ("How satisfied are you with your health?"). The rest of the 24 items, one from each facet of the WHOLQOL-100, were grouped into four domains: physical health (7 items, e.g., "How well are you able to get around?"), psychological (6 items, e.g., "How much do you enjoy life?"), social relationship (3 items, e.g., "How satisfied are you with your personal relationships?"), and environment (8 items, e.g., "How satisfied are you with the conditions of your living place?"). All items were scored on a 5-point response scale. Domain scores were calculated by multiplying the mean of all the facet scores within a domain by 4 to produce scores that are comparable with those in WHOQOL-100. Items 3, 4, and 26 were reverse coded so that 
a higher score indicated a higher quality of life. If more than one item was missing data from a domain, the score was not calculated. In this study, the internal consistency was marginal for physical health and psychological domains (0.70 and 0.71 , respectively) and acceptable for social relationship and environment domains (0.82 and 0.84 , respectively).

\section{Sociodemographic Variables, Smoking, and Comorbidities}

The participants were asked about their age, sex, religious affiliation, ethnicity, marital status, income, education, occupation, whether they had ever smoked, and whether they had diabetes and hypertension.

\section{Analysis}

To identify ethnic differences in Wave 1 data, ANOVAs and chi-square tests were conducted for continuous and categorical variables, respectively. We examined the cross-sectional association between religion and quality of life at Wave 1 using linear regression, adjusted for sociodemographics (age, ethnicity, sex, marital status, education, occupation, income, religion), comorbidities (hypertension, diabetes), and smoking status. We used linear regression to estimate the effects of Wave 1 religious variables on the change in quality of life score (Wave 2 quality of life-Wave 1 quality of life). The regression models were adjusted for Wave 1 sociodemographics (age, ethnicity, sex, marital status, education, occupation, income, and religion), comorbidities (hypertension and diabetes) and smoking status. As all Malays in Malaysia are legally Muslim, religious affiliation was excluded in the regressions involving Malay participants. Standardized regression coefficients were obtained for comparison between ethnic groups. Following Koenig et al.'s (Koenig, 2011) recommendation, we examined each religious variable separately instead of combining them in a single regression model. All regression models were stratified by ethnicity.

\section{Results}

\section{Descriptive Statistics}

Table 1 presents the characteristics of the samples from Wave 1 by ethnicity. From among the 3,810 participants in this study, 2,438 (63.4\%), 1,017 (26.7\%), and 355 (9.3\%) were Malays, Chinese, and Indians, respectively. The average age of participants was 63.8 years, and the Chinese were significantly older than the Malays and Indians. All Malays in this study were Muslim, while most Chinese were Buddhists (99.3\%) and most Indians were Hindus (86.2\% of all Indians). Significantly more Malays had incomes above RM1,000 (USD239) per month, followed by Chinese and Indians. Malays also had higher educational levels and employment rates. Significantly more Indians had diabetes, and more Malays self-reported "ever smoked." Chinese and Indians had higher rates of hypertension than Malays. 
Table 1 Characteristics of participants at wave 1 in $2013(N=3810)$

$\begin{array}{ll}\text { Malay }(N=2438), \text { mean } & \text { Chinese }(N=1017), \text { mean } \\ (S D) \text { or } N(\%) & (S D) \text { or } N(\%)\end{array}$

$(S D)$ or $N(\%)$

$(S D)$ or $N(\%)$

\begin{tabular}{|c|c|c|c|}
\hline Age*** & $63.3(6.69)$ & $65.5(7.48)$ & $62.5(6.23)$ \\
\hline \multicolumn{4}{|l|}{ Age group $* * *$} \\
\hline $55-64$ & $1594(65.4 \%)$ & $501(49.3 \%)$ & $244(68.7 \%)$ \\
\hline $65-74$ & $647(26.5 \%)$ & $395(38.8 \%)$ & $91(25.6 \%)$ \\
\hline 75 and above & $197(8.08 \%)$ & $121(11.9 \%)$ & $20(5.63 \%)$ \\
\hline \multicolumn{4}{|l|}{ Sex } \\
\hline Female & $1379(56.6 \%)$ & $549(54.0 \%)$ & $198(55.8 \%)$ \\
\hline Male & $1059(43.4 \%)$ & $468(46.0 \%)$ & $157(44.2 \%)$ \\
\hline \multicolumn{4}{|l|}{ Religion } \\
\hline Islam & $2438(100 \%)$ & $3(0.30 \%)$ & $0(0.00 \%)$ \\
\hline Buddhism & $0(0.00 \%)$ & $971(95.8 \%)$ & $8(2.25 \%)$ \\
\hline Hinduism & $0(0.00 \%)$ & $3(0.30 \%)$ & $306(86.2 \%)$ \\
\hline Christianity & $0(0.00 \%)$ & $15(1.48 \%)$ & $41(11.5 \%)$ \\
\hline Taoism & $0(0.00 \%)$ & $12(1.18 \%)$ & $0(0.00 \%)$ \\
\hline Other & $0(0.00 \%)$ & $10(0.99 \%)$ & $0(0.00 \%)$ \\
\hline \multicolumn{4}{|l|}{ Marital status } \\
\hline Married & $1918(78.8 \%)$ & $817(80.3 \%)$ & $273(76.9 \%)$ \\
\hline Widowed & $445(18.3 \%)$ & $149(14.7 \%)$ & $68(19.2 \%)$ \\
\hline Never married & $33(1.36 \%)$ & $38(3.74 \%)$ & $7(1.97 \%)$ \\
\hline Divorced/separated & $36(1.48 \%)$ & $10(0.98 \%)$ & $6(1.69 \%)$ \\
\hline Other & $1(0.04 \%)$ & $3(0.29 \%)$ & $1(0.28 \%)$ \\
\hline \multicolumn{4}{|l|}{ Individual income $e^{* * *}$} \\
\hline Less than RM1000 & $840(43.1 \%)$ & $427(51.4 \%)$ & $181(61.1 \%)$ \\
\hline More than RM1000 ${ }^{\dagger}$ & $1108(56.9 \%)$ & $403(48.6 \%)$ & $115(38.9 \%)$ \\
\hline \multicolumn{4}{|l|}{ Education $* * *$} \\
\hline No formal education & $46(1.93 \%)$ & $109(10.8 \%)$ & $20(5.65 \%)$ \\
\hline Primary & $1534(64.3 \%)$ & $616(61.0 \%)$ & $214(60.5 \%)$ \\
\hline Secondary & $626(26.3 \%)$ & $220(21.8 \%)$ & $103(29.1 \%)$ \\
\hline Tertiary & $46(1.93 \%)$ & $26(2.57 \%)$ & $5(1.41 \%)$ \\
\hline Other & $132(5.54 \%)$ & $39(3.86 \%)$ & $12(3.39 \%)$ \\
\hline \multicolumn{4}{|l|}{ Occupation $* * *$} \\
\hline Paid employee & $214(8.81 \%)$ & $218(21.5 \%)$ & $66(18.6 \%)$ \\
\hline Self-employed & $604(24.9 \%)$ & $136(13.4 \%)$ & $15(4.23 \%)$ \\
\hline Homemaker & $978(40.3 \%)$ & $300(29.6 \%)$ & $133(37.5 \%)$ \\
\hline Not working & $362(14.9 \%)$ & $226(22.3 \%)$ & $90(25.4 \%)$ \\
\hline Pensioner & $270(11.1 \%)$ & $135(13.3 \%)$ & $51(14.4 \%)$ \\
\hline \multicolumn{4}{|l|}{ Known Diabetes*** } \\
\hline Yes & $2068(84.8 \%)$ & $879(86.5 \%)$ & $238(67.0 \%)$ \\
\hline No & $370(15.2 \%)$ & $137(13.5 \%)$ & $117(33.0 \%)$ \\
\hline \multicolumn{4}{|c|}{ Known Hypertension $* * *$} \\
\hline Yes & $1982(81.3 \%)$ & $755(74.2 \%)$ & $261(73.5 \%)$ \\
\hline
\end{tabular}

Indian $(N=355)$, mean $(S D)$ or $N$

$(\%)$ 
Table 1 (continued)

\begin{tabular}{lll}
$\begin{array}{l}\text { Malay }(N=2438), \text { mean } \\
(S D) \text { or } N(\%)\end{array}$ & $\begin{array}{l}\text { Chinese }(N=1017), \text { mean } \\
(S D) \text { or } N(\%)\end{array}$ & $\begin{array}{l}\text { Indian }(N=355), \\
\text { mean }(S D) \text { or } N \\
(\%)\end{array}$ \\
\hline $456(18.7 \%)$ & $262(25.8 \%)$ & $94(26.5 \%)$ \\
$354(14.6 \%)$ & $92(9.06 \%)$ & $14(3.94 \%)$ \\
$2075(85.4 \%)$ & $923(90.9 \%)$ & $341(96.1 \%)$
\end{tabular}

Significant difference by ethnicity: $* * * p<.001$

${ }^{\dagger}$ RM1000 = USD239 (28 Oct 2019)

\section{Linear Regressions}

\section{Multivariate Analyses-Cross-sectional}

Religious importance was positively associated with general quality of life in all ethnic groups (Malay: $B=0.090$, SE $B=0.023, p<0.001$; Chinese: $B=0.158$, SE $B=0.031, p<0.001$; Indian: $B=0.150$, SE $B=0.059, p<0.05$ ) (Table 2) and health status among Malays and Chinese (Malay: $B=0.048$, SE $B=0.019, p<0.05$, Chinese: $B=0.125$, SE $B=0.032, p<0.001)$. A higher level of religious importance was associated with higher scores for psychological (Malay: $B=1.554$, SE $B=0.353$, $p<0.001$; Chinese: $B=2.514$, SE $B=0.584, p<0.001$ ), social relationship (Malays: $B=3.574$, SE $B=0.464, p<0.001$; Chinese: $B=1.482$, SE $B=0.743, p<0.05$ ), and environment domains (Malays: $B=2.182$, SE $B=0.374, p<0.005$; Chinese: $B=1.786$, SE $B=0.594, p<0.005$ ) among Malays and Chinese. For physical health domain, the association between religious importance was significant only among Chinese $(B=1.321$, SE $B=0597, p<0.05)$.

Table 2 Cross-sectional multiple linear regression of quality of life variables on religious importance $(N=3810)$

\begin{tabular}{|c|c|c|c|c|c|c|}
\hline \multirow[b]{2}{*}{ Variable } & \multicolumn{2}{|c|}{ Malay $(N=2438)$} & \multicolumn{2}{|c|}{ Chinese $(N=1017)$} & \multicolumn{2}{|c|}{ Indian $(N=355)$} \\
\hline & $B$ & SE $B$ & $B$ & SE $B$ & $B$ & SE $B$ \\
\hline General quality of life & $0.090 * * *$ & 0.023 & $0.158 * * *$ & 0.031 & $0.150 *$ & 0.059 \\
\hline Health status & $0.048 *$ & 0.019 & $0.125 * * *$ & 0.032 & 0.077 & 0.077 \\
\hline Physical health domain & 0.286 & 0.363 & $1.312^{*}$ & 0.597 & 0.134 & 1.241 \\
\hline Psychological domain & $1.554 * * *$ & 0.353 & $2.514 * * *$ & 0.584 & 1.006 & 1.167 \\
\hline Social relationship domain & $3.574 * * *$ & 0.464 & $1.482 *$ & 0.743 & -1.01 & 1.626 \\
\hline Environment domain & $2.182 * * *$ & 0.374 & $1.786^{* *}$ & 0.594 & -0.211 & 1.106 \\
\hline
\end{tabular}

Models were adjusted for age, ethnicity (for combined analysis), religious affiliation (except Malays), sex, marital status, education, occupation, income, diabetes (yes/no), hypertension (yes/no), and ever smoked (yes/no)

$* * * p<.001 . * * p<.01 . * p<.05$ 
A higher score for belief in a higher power control was significantly associated with poorer general quality of life among Malays $(B=-0.041$, SE $B=0.018$, $p<0.05)$, as well as better health status among Malays $(B=0.0002$, SE $B=0.015$, $p<0.0005)$ and Chinese $(B=0.057$, SE $B=0.025, p<0.05)$ (Table 3). A belief in a higher power control was positively associated with physical health (Malays: $B=0.867$, SE $B=0.282, p<0.01$; Chinese: $B=1.547$, SE $B=0.457, p<0.001$; Indians: $B=6.242$, SE $B=1.048, p<0.001$ ) and psychological (Malays: $B=0.668, \mathrm{SE}$ $B=0.274, p<0.05$; Chinese: $B=1.893$, SE $B=0.454, p<0.001$; Indians: $B=3.647$, SE $B=1.017, p<0.001)$ domains among all ethnic groups, and positively associated with social relationship among Chinese $(B=1.355$, SE $B=0.090, p<0.05)$ and Indians $(B=6.191$, SE $B=0.304, p<0.001)$ only. The association between a belief in a higher power control and environment domain was significant only among Indians $(B=2.516$, SE $B=0.126, p<0.05)$. The effect sizes for physical health, psychological, social relationship and environment domains among Indians were much higher than those of Malays and Chinese.

Overall, there was ethnic variation in the association between religiousness and quality of life, and the association was primarily positive.

\section{Multivariate Analyses-prospective}

A higher score of religious importance was significantly associated with a negative change in general quality of life, as well as the psychological, social relationship, and environment domains among the Malays (Table 4). The effect size for social relationship is much higher compared to the other variables (general quality of life: $B=-1.103$, SE $B=0.029, p<0.001$; psychological domain: $B=-1.408$, SE $B=0.451, p<0.001$; social relationship domain: $B=-3.566$, SE $B=0.598$, $p<0.001$; environment domain: $B=-1.971$, SE $B=-0.493, p<0.001$ ). Religious importance was negatively associated with all quality of life variables among the Chinese participants; however, the associations were only significant for general

Table 3 Cross-sectional multiple linear regression of quality of life variables on belief in a higher power control $(N=3810)$

\begin{tabular}{|c|c|c|c|c|c|c|}
\hline \multirow[b]{2}{*}{ Variable } & \multicolumn{2}{|c|}{ Malay $(N=2438)$} & \multicolumn{2}{|c|}{ Chinese $(N=1017)$} & \multicolumn{2}{|c|}{ Indian $(N=355)$} \\
\hline & $B$ & SE $B$ & $B$ & SE $B$ & $B$ & SE $B$ \\
\hline General quality of life & $-0.041 *$ & 0.018 & 0.038 & 0.025 & 0.094 & 0.054 \\
\hline Health status & $0.0002 * * *$ & 0.015 & $0.057 *$ & 0.025 & 0.119 & 0.069 \\
\hline Physical health domain & $0.867 * *$ & 0.282 & $1.547 * * *$ & 0.457 & $6.242 * * *$ & 1.048 \\
\hline Psychological domain & $0.668^{*}$ & 0.274 & $1.893 * * *$ & 0.454 & $3.647 * * *$ & 1.017 \\
\hline Social relationship domain & 0.677 & 0.351 & $1.355^{*}$ & 0.09 & $6.191 * * *$ & 0.304 \\
\hline Environment domain & -0.334 & 0.294 & 0.684 & 0.048 & $2.156 *$ & 0.126 \\
\hline
\end{tabular}

Models were adjusted for age, ethnicity (for combined analysis), religious affiliation (except Malays), sex, marital status, education, occupation, income, diabetes (yes/no), hypertension (yes/no), and ever smoked (yes/no)

$* * * p<.001 . * * p<.01 . * p<.05$ 
Table 4 Change of quality of life (Wave 2-Wave 1) regressed on religious importance in wave 1 $(N=3810)$

\begin{tabular}{|c|c|c|c|c|c|c|}
\hline \multirow[b]{2}{*}{ Variable } & \multicolumn{2}{|c|}{ Malay $(N=2438)$} & \multicolumn{2}{|c|}{ Chinese $(N=1017)$} & \multicolumn{2}{|c|}{ Indian $(N=355)$} \\
\hline & $B$ & SE $B$ & $B$ & SE $B$ & $B$ & SE $B$ \\
\hline General quality of life & $-0.103 * * *$ & 0.029 & $-0.160 * * *$ & 0.043 & -0.089 & 0.087 \\
\hline Health status & -0.029 & 0.027 & $-0.083^{*}$ & 0.042 & 0.005 & 0.095 \\
\hline Physical health domain & 0.433 & 0.479 & -0.007 & 0.761 & 0.044 & 1.578 \\
\hline Psychological domain & $-1.408 * *$ & 0.451 & $-0.076^{*}$ & 0.792 & -0.006 & 1.611 \\
\hline Social relationship domain & $-3.566 * * *$ & 0.598 & -0.023 & 0.923 & 0.058 & 2.060 \\
\hline Environment domain & $-1.974 * * *$ & 0.493 & -0.049 & 0.771 & 0.019 & 1.449 \\
\hline
\end{tabular}

Models were adjusted for age, ethnicity (for combined analysis), religious affiliation (except Malays), sex, marital status, education, occupation, income, diabetes (yes/no), hypertension (yes/no), and ever smoked (yes/no)

$* * * p<.001 . * * p<.01 . * p<.05$

quality of life $(B=-0.160$, SE $B=0.043, p<0.001)$, health status $(B=-0.083$, SE $B=0.042, p<0.05)$ and psychological domain $(B=-0.076$, SE $B=0.92, p<0.05)$. The effect size for the psychological domain for Malays was much larger than that of Chinese. There was no significant association between religious importance and all quality of life variables among the Indians.

A higher score for belief in a higher power control was significantly associated with a higher score for the general quality of life, but this was limited to Malays only $(B=0.051$, SE $B=0.022, p<0.05)$ and was not associated with health status in all ethnic groups (Table 5). Next, it was strongly associated with a negative change in the physical health, psychological, social relationship, and environment domains among the Indians (physical health domain: $B=-5.412$, SE $B=1.382, p<0.001$; psychological domain: $B=-3.325$, SE $B=1.42, p<0.001$; social relationship

Table 5 Change of quality of life (Wave 2-Wave 1) regressed on belief in a higher power control in wave $1(N=3810)$

\begin{tabular}{|c|c|c|c|c|c|c|}
\hline \multirow[b]{2}{*}{ Variable } & \multicolumn{2}{|c|}{ Malay $(N=2438)$} & \multicolumn{2}{|c|}{ Chinese $(N=1017)$} & \multicolumn{2}{|c|}{ Indian $(N=355)$} \\
\hline & $B$ & SE $B$ & $B$ & SE $B$ & $B$ & SE $B$ \\
\hline General quality of life & $0.051^{*}$ & 0.022 & -0.037 & 0.034 & -0.065 & 0.078 \\
\hline Health status & 0.009 & 0.021 & -0.028 & 0.033 & -0.126 & 0.085 \\
\hline Physical health domain & -0.535 & 0.372 & -0.351 & 0.589 & $-5.412 * * *$ & 1.382 \\
\hline Psychological domain & -0.469 & 0.351 & -0.978 & 0.614 & $-3.325 * * *$ & 1.423 \\
\hline Social relationship domain & -0.375 & 0.450 & -0.319 & 0.665 & $-5.548 * * *$ & 1.616 \\
\hline Environment domain & 0.250 & 0.382 & 0.296 & 0.602 & $-2.886^{*}$ & 1.288 \\
\hline
\end{tabular}

Models were adjusted for age, ethnicity (for combined analysis), religious affiliation (except Malays), sex, marital status, education, occupation, income, diabetes (yes/no), hypertension (yes/no), and ever smoked (yes/no)

$* * * p<.001 .{ }^{*} p<.05$ 
domain: $B=-5.548$, SE $B=1.616, p<0.001$; environment domain: $B=-2.586$, SE $B=1.288 ; p<0.05$ ) but not associated with the four domains among the Malays and Chinese.

Overall, the association between religiousness and the change in the quality of life was mostly negative or nil in the two-wave longitudinal analysis.

\section{Discussion}

The association between religiousness and quality of life among older adults has not been extensively explored in non-Christian and non-White populations. The current study filled the knowledge gap by investigating the cross-sectional and longitudinal relationships between religiousness and quality of life among older adults living in a predominantly Muslim and multicultural setting in Malaysia. As predicted, this study showed ethnic variations in the associations between religiousness and quality of life. The associations between religiousness and quality of life were mainly positive in the cross-sectional analysis at baseline but negative or nil in the two-wave (data collected five years apart) longitudinal analysis.

In the cross-sectional analysis, religious importance was associated with a better general quality of life in all ethnic groups. Religious importance was also associated with better health status among the Malays and the Chinese and higher scores in all the quality of life domains among the Malays and the Chinese (except physical health domain among the Malays, where the association was nonsignificant). A belief in a higher power control was associated with higher scores of health status, physical health, and psychological domains among the Malays and the Chinese, a higher score of social relationship domain among the Chinese and the Indians, and a higher score of environment domain among the Indians. It was, however, negatively associated with general quality of life among the Malays.

The cross-sectional analysis results were consistent with previous studies conducted between 2000 and 2012, mostly among Christian and White populations. The majority of the studies (64\%, or 41 out of 64), which were primarily cross-sectional, identified a positive association between a higher level of religiousness and a better quality of life (Koenig et al., 2012). A study in 18 countries conducted by the WHOQOL Spirituality, Religiousness and Personal Beliefs Group found that spirituality, religion, and personal beliefs are positively and significantly correlated with the psychological and social relationship domains as well as the overall quality of life (WHOQOL SRPB Group, 2006).

Our study's two-wave analysis showed that among the Malays, a higher score in religious importance at Wave 1 predicted a negative change in the general quality of life and the psychological, social relationship, and environment domains. Belief in a higher power control at Wave 1 was not associated with quality of life variables among the Malays, except for a weak positive association with the general quality of life. Among the Chinese, higher religious importance at Wave 1 was associated with a negative change of general quality of life, health status, and psychological domain. However, belief in a higher power control at Wave 1 was not associated with all quality of life variables. Among the Indians, religious importance at Wave 1 was not 
associated with all quality of life measures. In contrast, belief in a higher power control at Wave 1 was strongly associated with a negative change in the physical health, psychological, social relationship, and environment domains.

The mixed results from the two-wave longitudinal analysis were consistent with the handful of longitudinal studies on religion and quality of life. Of the six prospective cohort studies included in the systematic review mentioned previously, only one found a positive association between religiousness and quality of life (Frame et al., 2005). The other studies mostly had negative, nonsignificant, or mixed findings (Kim et al., 2009; Mrus et al., 2006; Pargament et al., 2004; Robbins et al., 2001; Trevino et al., 2010). Past longitudinal studies that found a negative association between religion and quality of life had examined the negative dimensions of religion, such as religious struggle and negative religious coping. For example, in a study of 429 HIV/AIDS patients by Trevino (Trevino et al., 2010), spiritual struggle was negatively associated with the quality of life. Longitudinal studies that examined religious belief (e.g., religious worldview) and the behavioral aspects of religion (e.g., attendance, prayers) mostly showed no association with quality of life. Our study included religious variables that gauged religious beliefs. We found that their longitudinal association with quality of life was either negative or nil. The association between religiousness and quality of life may differ between cultures and religions. In our previous study of the association between religion and mental health at the same research site, we found similar ethnic variations and mixed associations (Tan et al., 2020).

If the association between religiousness and quality of life does not change over time, then the cross-sectional associations should be similar to the longitudinal associations. However, the variation in the results between the cross-sectional and twowave longitudinal analyses in our study indicate that other factors could be influencing the associations. In a cross-sectional study, an inverse relationship cannot be ruled out where people with a better quality of life have higher religiousness, which might explain the positive association in the cross-sectional analysis of our study. In the longitudinal analysis, older adults who were more religious either had negative or no change in their quality of life.

The association between religion and negative change of quality of life in our study might be explained by fatalism, a specific personal control construct and a belief that whatever happens has been decreed and is mostly beyond one's control. Compared to Westerners, Asians believe more in fatalism and less in personal control of life regardless of their religious affiliations (Norenzayan \& Lee, 2010). Fatalistic views have been found to mediate the association between religious orientation and quality of life. Those people with a higher extrinsic religious orientation had a more fatalistic view of life and a poorer quality of life (Mohammadi et al., 2017).

In this study, another possible explanation for the negative association between religiousness and quality of life could be the lower average household income at Segamat district, where the study was conducted, compared to other districts in Malaysia. In Turkey, among individuals from the lower-income group, a higher rating of importance of faith was significantly associated with lower quality of life, whereas the association was not significant among those from the higher-income group (Sandikc1 et al., 2016). The median monthly household income (RM4,609 or 
USD1,049) in Segamat is about 44\% lower than that in Sepang, the district with the highest median monthly household income (RM8,174 or USD1,861) in Malaysia (Department of Statistics Malaysia, 2020). While past studies have shown that religion might act as a buffer against the effect of financial hardship on mental health among economically disadvantaged people (Bradshaw \& Ellison, 2010), this might not be the case in our study.

In the two-wave analysis, there was no significant association between religious importance and quality of life among the Chinese and the Indians or between belief in a higher power control and quality of life among the Malays and the Chinese. A possible explanation for the nonsignificant association might be that a positive association was found at baseline (as shown in the cross-sectional analysis), and it was maintained at the follow-up. That is, there were no further changes in quality of life.

Among the Chinese participants, the relationship between religiousness and quality of life in the two-wave analysis was mostly nonsignificant. Compared to the Malays and the Indians, the Chinese were the least religious; they had the lowest mean scores in religious importance and belief in a higher power control in 2013 and 2018. While most Chinese in Malaysia self-reported to be Buddhists, their beliefs are syncretic, consisting of indigenous Chinese cults and Buddhist beliefs as well as practices from various Buddhist traditions (Theravada, Mahayana and Vajrayana) (C.-B. Tan, 1983). Furthermore, the religious variables in this study might not capture traditional Chinese beliefs, which would need to be measured by ritualistic behaviors such as the offering of incense or sacrifices (Ting et al., 2020).

\section{Study Limitations}

Several study limitations are worthy of highlighting. First, the self-rated item on the importance of having an enriched religious/spiritual life did not have options for being unimportant or not useful. It could, thus, bias the results toward a positive appraisal of religious importance. Second, our study only included two single-item religious scales. Other important religious measures such as "spiritual struggle" and "religious coping," which have been shown to be associated with quality of life, were excluded. Single-item measures of religiousness might not be appropriate if it is too superficial or its reliability cannot be determined. In addition, a single-item scale aggregates all different effects of religion into one scale and this might prevent the identification of the effect in opposite directions (Koenig, 2011). A further limitation of this study is the close interrelationship between religion and ethnicity in Malaysia. All Malays are Muslims, the majority of Chinese are Buddhist, and the majority of Indians are Hindu. We were, therefore, unable to tease apart the influence of ethnicity and religion. It may be that, for instance, the apparent ethnic differences in the associations between religion and quality of health were actually due to different religious affiliations across the ethnic groups.

Taking into consideration the limitations of the current study, future research on religion and health in Malaysia and other Asian countries should utilize multiitem religious scales, such as religious coping, tailored to the different ethnic/religious groups. Additionally, future studies should consider the inclusion of more 
participants with other combinations of ethnicities and religions (e.g., Chinese and Indians who are Christians or Muslims). These intersections between ethnicity and religious belief make it difficult (and potentially incoherent) to analyze religion in isolation from ethnicity. However, it also provides a paradigm for future ethnoreligious studies, as many ethnic groups (such as Jews, Arabs, and Tibetans) still adhere to traditional religions that tie into their ethnic traditions. Future studies could purposively examine the intersectional identity of one particular group, rather than attempt to isolate one religion or one ethnic group at a time.

Despite these limitations, the strength of the study is in the analysis of two-waves of data, which allowed us to determine whether a change in the quality of life over five years is associated with religiousness. The majority of religion and health studies are cross-sectional, outnumber longitudinal studies by a six-to-one ratio (Koenig et al., 2012), and were conducted among the Christian, often White populations. Our study, on the other hand, examined a predominantly Muslim population in a multicultural setting in Malaysia. Consistent with studies in Western countries, the results of this study also demonstrate ethnic variations in the association between religion and quality of life. The results of the current study might be applicable to other Asian countries, where Islam, Buddhism, and Hinduism are considered the major religions.

\section{Conclusion}

With a continuous rise in life expectancy, the proportion of individuals over the age of 60 is increasing rapidly, especially in low- and middle-income countries (Shrestha, 2000). Given the increased importance of religion among older adults, our study has important public health implications. Aging is associated with physical, psychological, and cognitive decline, in addition to the loss of social support and increased loneliness. The findings of our study suggest that when evaluating potential health risks among older adults, it is important to include religious and spiritual dimensions as well as physical and psychological factors. While past studies have shown a positive association between religion and better health, the negative and nonsignificant results in our study suggest that religiousness might not always be compatible with quality of life outcomes.

Future studies should also seek to identify specific dimensions of religion that could be targeted to improve the quality of life among older adults, especially in the Asian populations which have different cultural beliefs than their Western counterparts. Since the positive association between religiousness and quality of life is short-lived (as seen in the cross-sectional but not in the two-wave analysis), health promotion programs should continue to examine the effects of religiousness across timelines such as community accessibility to various religious facilities and services for aging populations. Multireligious sensitivity should be considered when conducting community outreach to recognize the heterogeneous ethnoreligious groups (Ting \& Ng, 2012). In conclusion, this study has identified religiousness as a possible determinant of quality of life among older adults in a predominantly Muslim 
and multicultural setting. The research findings could help to pave the way toward effective health promotion programs among religious communities.

Acknowledgements The authors would like to express their appreciation to the SEACO Field Team and members of the SEACO Scientific Advisory Group.

Author Contributions MM Tan, TT Su, P Allotey, and DD Reidpath conceptualized and planned the study; MM Tan conducted statistical analyses and drafted the manuscript in consultation with TT Su; TT Su verified the analytical methods and revised the paper; RSK Ting and DD Reidpath revised/edited the paper; all authors provided critical feedback and helped shape the research, analysis and manuscript.

Funding This work was supported by the John Templeton Foundation (Grant number: 60839), "Religion and physical and mental health among elderly in a predominantly Muslim and multicultural community: the causal linkages."

Data Availability Data are available from the corresponding authors upon reasonable request.

Code Availability The $\mathrm{R}$ codes are available from the corresponding authors upon reasonable request.

\section{Declarations}

Conflict of interest The authors declare no conflicts of interest.

\section{References}

Assari, S. (2013). Race and ethnicity, religion involvement, church-based social support and subjective health in United States: A case of moderated mediation. International Journal of Preventive Medicine, 4(2), 208-217.

Bradshaw, M., \& Ellison, C. G. (2010). Financial hardship and psychological distress: Exploring the buffering effects of religion. Social Science and Medicine, 71(1), 196-204.

Chokkanathan, S. (2013). Religiosity and well-being of older adults in Chennai India. Aging and Mental Health, 17(7), 880-887. https://doi.org/10.1080/13607863.2013.790924

Department of Statistic Malaysia. (2011). Population distribution and basic demographic characteristics 2010. https://www.mycensus.gov.my/index.php/census-product/publication/census-2010/ 659-population-distribution-and-basic-demographic-characteristics-2010

Department of Statistics Malaysia. (2019). Current population estimates, Malaysia, 2018-2019. https://www.dosm.gov.my/v1/index.php?r=column/cthemeByCat\&cat=155\&bul_id=aWJZR kJ4UEdKcUZpT2tVT090Snpydz09\&menu_id=L0pheU43NWJwRWVSZk1WdzQ4T1hUUT09

Department of Statistics Malaysia. (2020, February). Poket Stats Negeri Johor: ST4 2019 [Pocket Stats for Johor State: ST4 2019]. https://www.dosm.gov.my/v1/uploads/files/7_Publication/Infog raphic/PocketStats/Negeri/Johor/Q4-2019/Poket_Stats_Johor_ST4_2019.pdf

Frame, M. W., Uphold, C. R., Shehan, C. L., \& Reid, K. J. (2005). Effects of spirituality on healthrelated quality of life in men with HIV/AIDS: Implications for counseling. Counseling and Values, 50(1), 5-19. https://doi.org/10.1002/j.2161-007X.2005.tb00037.x

Ibrahim, S. A., Burant, C. J., Siminoff, L. A., Stoller, E. P., \& Kwoh, C. K. (2002). Self-assessed global quality of life: A comparison between African-American and white older patients with arthritis. Journal of Clinical Epidemiology, 55(5), 512-517. https://doi.org/10.1016/s08954356(01)00501-7

Jahan, N. K., Allotey, P., Arunachalam, D., Yasin, S., Soyiri, I. N., Davey, T. M., \& Reidpath, D. D. (2014). The rural bite in population pyramids: What are the implications for responsiveness of health systems in middle income countries? BMC Public Health, 14(2), S8. https://doi.org/10. 1186/1471-2458-14-S2-S8 
Kim, J., Nesselroade, J. R., \& McCullough, M. E. (2009). Dynamic factor analysis of worldviews/religious beliefs and well-being among older adults. Journal of Adult Development, 16(2), 87-100. https://doi.org/10.1007/s10804-009-9062-2

Koenig, H. G. (2011). Spirituality and health research: Methods, measurement, statistics and resources. Templeton Press.

Koenig, H. G., King, D. E., \& Carson, V. B. (2012). Handbook of religion and health (2nd ed.). Oxford University Press.

Krause, N., \& Hayward, R. D. (2016). Religion, health, and aging. In L. George \& K. Ferraro (Eds.), Handbook of aging and the social sciences (pp. 251-270). Academic Press.

Mohammadi, M., Danesh, E., \& Taghiloo, S. (2017). The mediating role of time perspective in the relationship between religious orientation and quality of life. Journal of Fundamentals of Mental Health, 20(1), 75-86.

Momtaz, Y., Hamid, T. A., Ibrahim, R., Yahaya, N., \& Abdullah, S. S. (2012). Moderating effect of Islamic religiosity on the relationship between chronic medical conditions and psychological well-being among elderly Malays. Psychogeriatrics, 12(1), 43-53. https://doi.org/10.1111/j. 1479-8301.2011.00381.X

Mrus, J. M., Leonard, A. C., Yi, M. S., Sherman, S. N., Fultz, S. L., Justice, A. C., \& Tsevat, J. (2006). Health-related quality of life in veterans and nonveterans with HIV/AIDS. Journal of General Internal Medicine, 21(S5), S39-S47. https://doi.org/10.1111/j.1525-1497.2006.00644.x

Norenzayan, A., \& Lee, A. (2010). It was meant to happen: Explaining cultural variations in fate attributions. Journal of Personality and Social Psychology, 98(5), 702-720. https://doi.org/10.1037/ a0019141

Pargament, K. I., Koenig, H. G., Tarakeshwar, N., \& Hahn, J. (2004). Religious coping methods as predictors of psychological, physical and spiritual outcomes among medically ill elderly patients: A two-year longitudinal study. Journal of Health Psychology, 9(6), 713-730. https://doi.org/10. $1177 / 1359105304045366$

Partap, U., Young, E. H., Allotey, P., Soyiri, I. N., Jahan, N., Komahan, K., Devarajan, N., Sandhu, M. S., \& Reidpath, D. D. (2017). HDSS profile: The South East Asia community observatory health and demographic surveillance system (SEACO HDSS). International Journal of Epidemiology, 46(5), 1370-1371g. https://doi.org/10.1093/ije/dyx113

Robbins, R. A., Simmons, Z., Bremer, B. A., Walsh, S. M., \& Fischer, S. (2001). Quality of life in ALS is maintained as physical function declines. Neurology, 56(4), 442-444. https://doi.org/10. 1212/wnl.56.4.442

Sandıkc1, Ö., Peterson, M., Ekici, A., \& Simkins, T. (2016). Development and quality of life in Turkey: How globalization, religion, and economic growth influence individual well-being. Journal of Macromarketing, 36(3), 304-320. https://doi.org/10.1177/0276146715608919

Shiah, Y.-J., Chang, F., Chiang, S.-K., \& Tam, W.-C.C. (2016). Religion and subjective well-being: Western and eastern religious groups achieved subjective well-being in different ways. Journal of Religion and Health, 55(4), 1263-1269. https://doi.org/10.1007/s10943-014-9905-4

Shrestha, L. B. (2000). Population aging in developing countries. Health Affairs, 19(3), $204-212$. https://doi.org/10.1377/hlthaff.19.3.204

Tan, C.-B. (1983). Chinese religion in Malaysia: A general view. Asian Folklore Studies, 42(2), 217252. https://doi.org/10.2307/1178483

Tan, M. M., Su, T. T., Ting, S.-K., Allotey, P., \& Reidpath, D. (2020). Religion and mental health among older adults: Ethnic differences in Malaysia. Aging \& Mental Health. Advance Online Publication. https://doi.org/10.1080/13607863.2020.1799939

Ting, R.S.-K., Mah, S.-C., \& Zhang, K. (2020). Chinese traditional religions and mental health: An indigenous psychology perspective. In T. A. Sisemore \& J. J. Knabb (Eds.), The psychology of world religions and spiritualities (pp. 237-262). Templeton Press.

Ting, R.S.-K., \& Ng, A. L. O. (2012). Use of religious resources in psychotherapy from a traditionsensitive approach: Cases from Chinese in Malaysia. Pastoral Psychology, 61(5-6), 941-957. https://doi.org/10.1007/s11089-011-0365-4

Trevino, K. M., Pargament, K. I., Cotton, S., Leonard, A. C., Hahn, J., Caprini-Faigin, C. A., \& Tsevat, J. (2010). Religious coping and physiological, psychological, social, and spiritual outcomes in patients with HIV/AIDS: Cross-sectional and longitudinal findings. AIDS and Behavior, 14(2), 379-389. https://doi.org/10.1007/s10461-007-9332-6

WHOQoL Group, \& W . (1998). Development of the World Health Organization WHOQOL-BREF quality of life assessment. Psychological Medicine, 28(3), 551-558. 
WHOQOL SRPB Group. (2006). A cross-cultural study of spirituality, religion, and personal beliefs as components of quality of life. Social Science and Medicine, 62(6), 1486-1497. https://doi.org/ 10.1016/j.socscimed.2005.08.001

World Health Organization. (2012). Measuring Quality of Life. https://www.who.int/healthinfo/survey/ whoqol-qualityoflife/en/

Publisher's Note Springer Nature remains neutral with regard to jurisdictional claims in published maps and institutional affiliations.

\section{Authors and Affiliations}

\section{Min Min Tan ${ }^{1,2}$ D $\cdot$ Daniel D. Reidpath ${ }^{2,5} \cdot$ Rachel Sing-Kiat Ting ${ }^{3}$. Pascale Allotey ${ }^{2,4} \cdot$ Tin Tin Su $^{1,2}$}

1 South East Asia Community Observatory (SEACO), Jeffrey Cheah School of Medicine and Health Sciences, Monash University Malaysia, Jalan Lagoon Selatan, Bandar Sunway, 47500 Subang Jaya, Selangor, Malaysia

2 Jeffrey Cheah School of Medicine and Health Sciences, Monash University Malaysia, Jalan Lagoon Selatan, Bandar Sunway, 47500 Subang Jaya, Selangor, Malaysia

3 Department of Psychology, Jeffrey Cheah School of Medicine and Health Sciences, Monash University Malaysia, Jalan Lagoon Selatan, Bandar Sunway, 47500 Subang Jaya, Selangor, Malaysia

4 United Nations University International Institute for Global Health (UNU-IIGH), UKM Medical Centre, Jalan Yaacob Latif, Bandar Tun Razak, Cheras, 56000 Kuala Lumpur, Malaysia

5 Health System and Population Studies Division, International Centre for Diarrhoeal Disease Research, Bangladesh, Mohakhali, Dhaka 1212, Bangladesh 